\title{
Towards Process-Oriented Ontology for Financial Analysis
}

\author{
Jerzy Korczak, Helena Dudycz, Bartłomiej Nita, Piotr Oleksyk \\ Wrocław University of Economics Komandorska Str. 118/120, \\ PL 53-345 Wroclaw, Poland \\ Email: \{jerzy.korczak, helena.dudycz, bartlomiej.nita, piotr.oleksyk\}@ue.wroc.pl
}

\begin{abstract}
The article presents an approach to integrate a business process knowledge of Decision Support Systems. It concerns two major aspects of the system, i.e. the formalization of processes predefined in Business Process Modeling Notation, the reuse of a domain ontology, and the analysis of economic and financial information. The described approach is a continuation of the construction of the intelligent cockpit for managers (InKoM project), whose main objective was to facilitate financial analysis and the evaluation of the economic status of the company in a competitive market. The current project is related to the design of smart decision support systems based on static (structural) and procedural knowledge. The content of the knowledge is focused on essential financial concepts and relationships related to the management of small and medium enterprises (SME). An experiment was carried out on real financial data extracted from the financial information system.
\end{abstract}

\section{INTRODUCTION}

$\mathrm{M}$ ANAGING an enterprise requires access to the appropriate Decision Support System (DSS) that must always go hand in hand with the methods and tools of financial analysis. The problem is that managers of SMEs often do not possess a solid background in financial analysis and IT technology to strengthen their competitive position on the market and maintain financial credibility. The problem is often caused by the lack of the knowledge required to correctly interpret economic indicators. Moreover, these studies have shown difficulties for the knowledgeable use of information systems that contain too many functions and tools that exceed the manager's competencies.

The essence of financial analysis is to address various problems of the current short-term decision making as well as long-term strategic planning. Both types of the decisions made refer to the appropriate level of debt. Liabilities include necessary sources of business financing, however, are also an important cause of financial risk, and may lead to bankruptcy [1]. The main factor associated with financial obligations is the lack of internally generated funds allowing for their repayment.

Taking into consideration all managerial requests and the complexity of business problems, solutions are needed that integrate managerial knowledge in DSSs and support intelligent analysis and decision making [2]. One of the main obstacles for automation of analytical processes within current DSS is the lack of a formal representation of the procedural knowledge within models of business processes. In most of the systems, the operations within the processes are defined diagrammatically, in natural language or pseudo Pascal notation which makes this representation very informal and ambiguous. In consequence, the reasoning tasks and computation are very limited.

The aim of the paper is to propose an approach that integrates financial knowledge, analytical models, and business reasoning. In the project, it is assumed that the financial knowledge is formally defined by the domain ontology. The analytical models as well as business reasoning rules are known in the literature and can be easily encoded. The essential part of the work is to develop the system that enables automated analysis of information available in financial databases and reports. The idea of the project is partially inspired by works on modelling business process knowledge, notably F. Smith and D. Proietti [3], A. De Nicola, M. Lezoche and M. Missikoff [4]. The process of analysis is to be defined using the Business Process Model and Notation (BPMN) extended by the domain ontology in OWL and a process knowledge encoded in Business Process Abstract Language (BPAL). Ontology, representing structural and procedural knowledge, seems to be a key element in the DSS that will support a manager to make correct business decisions, oriented toward company prosperity.

The paper is structured as follows. The first part briefly introduces the economic and technological background of financial analysis. The analytical activities are described as a business process diagram in BPMN, extended by the financial ontology. In the next section the design methodology of process-oriented ontology is briefly discussed. The presentation is focused on formal aspects of procedural knowledge specification. In Section 4 the use case is detailed using real life data extracted from a financial information system. The analytical activities are specified formally in a language close to BPAL and illustrated by the analysis of financial data. The whole analytical process is decomposed to subprocesses, activities, and tasks, and completed by the required information resources. The specifications focus on one of the key issues of financial 
analysis related to the processes of emergency policy. Finally, in the last section, some conclusions are drawn and the future of the project discussed.

\section{II.FOUNDATIONS OF AUTOMATION OF ANALYTICAL PROCESSES}

The problems associated with assuring on-going continuation of business operations in their current form and size are very common in practice. Managers are obliged to evaluate on a constant basis the ability of a company to operate in the future. Thus, lack of meeting this requirement may result in legal sanctions against managers. One of the most common reasons for solvency problems and the inability of a company to continue its operations is an excessive amount of liabilities in relation to equity or total assets. Among the most common restructuring activities is to strive for eliminating excessive financial liabilities. Business practice has developed many ways to reduce liabilities [5, p. 995].

Key Performance Indicators (KPI) analysis is a comprehensive method used by financial analysts to evaluate the financial standing of a company and support managers in the decision making process. This is due to the fact that the set of financial indicators and metrics allows for multifaceted evaluation of the validity and effectiveness of the financial obligations. While building financial ratios, it is possible to compare liabilities with various items included in the balance sheet, and profit and loss account, as well as cash flow statement. The most commonly used indicator in assessing company equity is Debt to Equity Ratio (computed as relation between Total Liabilities and Equity). The lower the ratio the better financial position of the company. This ratio is used not only by banks, but also by potential investors. This is why managers want to maintain company equity in excess of the financial obligations or want to systematically decrease liabilities while simultaneously increasing capital.

The process of financial analysis can be represented as a workflow graph describing the correct sequence of operations, where each operation described involves concepts, data items, and the relations between them. To model the analytical operations, Business Process Modeling and Notation (BPMN) will be applied (http://www.omg.org). Usually, a BPMN model is defined through a Business Process Diagram (BPD), which is a kind of flowchart incorporating constructs to represent the control flow, data flow, the work to be assigned to the participants, and handling of exceptions. In the project, a process of analysis is composed of an interrelated set of subprocesses or activities, where an activity is formed by sub-activities or tasks. A task is an atomic element that cannot be decomposed. Fig.1 illustrates an example of BPD referring to the analysis of financial situation of a company.

The presented BPD describes the order of analytical processes and the related financial concepts. The process starts with the request for financial data. The detailed information about the sources and market signals will be explained in Section 4. After having received the data of the subprocess of KPI's evaluation starts, among other things, the task of assessing Debt to_Equity_Ratio discussed in the paper. The presentation focuses only on processes to be executed within Emergency Policy (shown on the left side of Fig. 1). On the right part of the analytical, three key subprocesses end the whole process, namely:

- Financial Recovery Program through increasing sales revenues and decreasing debt ratio;

- Conversion of Liabilities into Equity,

- Commencement of Bankruptcy Procedure.

The specifications of all subprocesses will be detailed in section 4.

Each of these key subprocesses is based on information derived from the financial statements, projections of future performance on the cost of debt, and the scale of business operations in the future. A full explanation of these complex financial issues is beyond the scope of the article.

The workflow model of financial analysis describes the process enactment but does not contain information on the domain knowledge. Therefore, in the project, the financial ontology has been added. The ontology provides semantic annotations of the entities, objects, items and pre- and postconditions involved in the sub-processes. In order to define the semantics, the Ontology Web Language (OWL) was used. A part of the ontology related to the solvency threat is illustrated on the top left of Fig.1. The Description Logics used in OWL represents the domain concepts in a form of TBoxes and the assertions as ABoxes. For instance, TBox may describe a concept of hierarchy, (e.g., Balance_Sheets $\subseteq$ Financial_Reports $1 \exists$ report-edBy.Company). An example of ABox is an assertion about an individual can be written as follows: Bal-ance2016.Company : Balance_Sheets. OWL is syntactically layered on RDF. The underlying data model (derived from RDF) is based on statements (or RDF triples) of the form < subject; property; object $>$, which allow us to define a resource (subject) in terms of named relations (properties). Values of named relations (i.e. objects) can be URIrefs of Web resources or literals, i.e. representations of data values.

In the project, the financial ontology has been encoded using the Protégé platform (http://protege.stanford.edu/). It is important to note that the given ontology describes only static structures, namely the financial concepts and their relationships. The ontology presented in Fig. 1 shows a few concepts related to Key_Performance_Indicators analysis (marked by a green border). On the screen-shot, the Solvency Threat area is encircled by a red solid line. In this screenshot there are two types of lines between topics: (1) the solid line represents a relation Subclass-of and (2) the dashed line represents the experts' defined relationship (for example: depends on). 


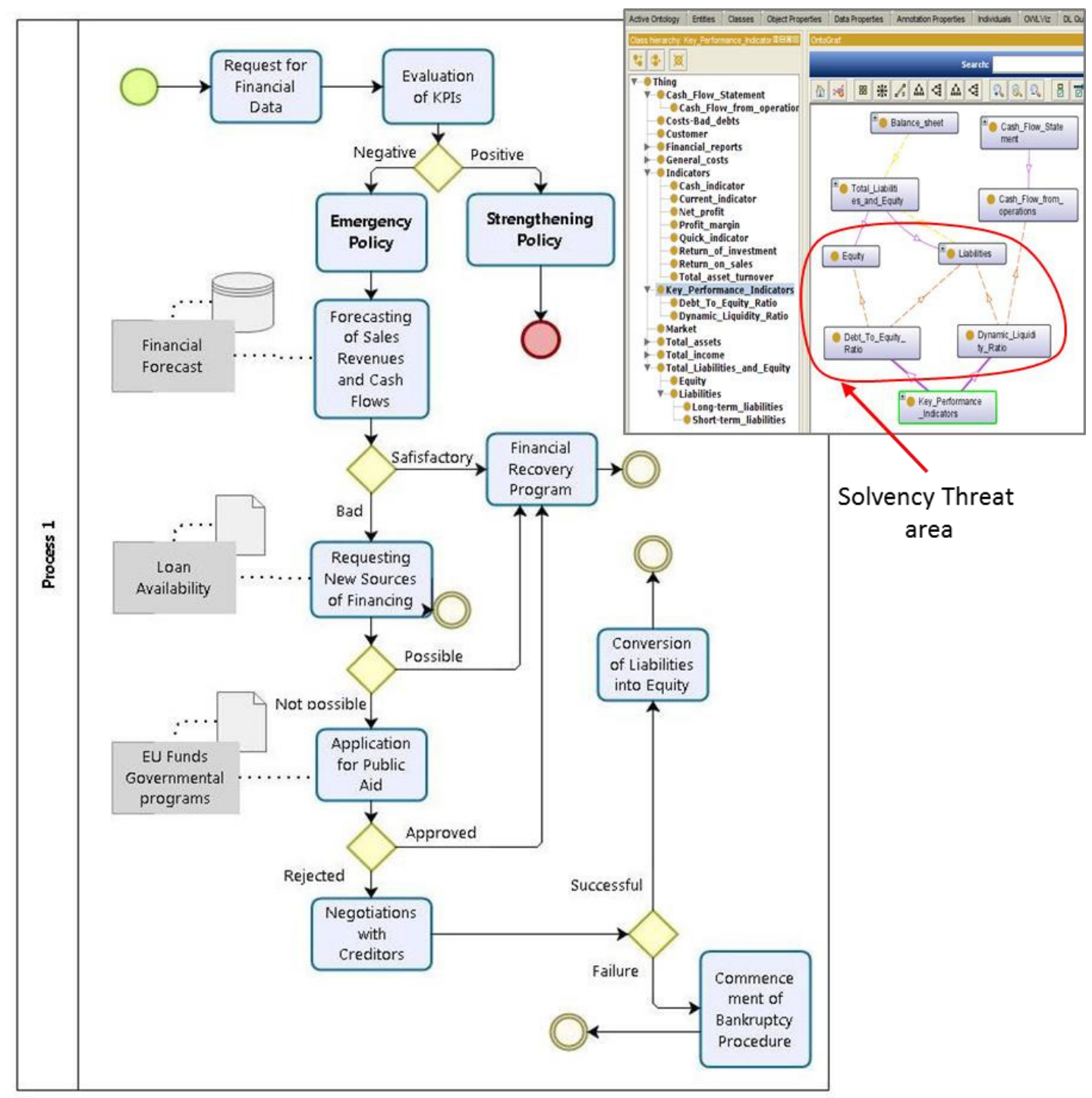

Fig. 1. Diagram of processes of financial data analysis

Source: own elaboration.

The created ontology illustrated on fig. 1 can be presented as OWL code as follows:

\section{$<!$ DOCTYPE Ontology [}

$<$ Declaration $><$ Class IRI $=$

"\#Debt_to_Equity_Ratio" $>></$ Declaration $>$

$<$ Declaration $><$ Class IRI $=$

"\#Dynamic_Liquidity_Ratio"/></Declaration $>$

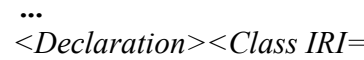

"\#Key Performance Indicators" $/></$ Declaration $>$

$<$ Declaration $><$ Class IRI $=$ "\#Liabilities" $/></$ Declaration $>$

...

$<$ Declaration $><$ ObjectProperty IRI $=$ "\#contains" $>></$ Declaration $>$

$<$ Declaration $><$ ObjectProperty IRI $=$ "\#depends_on"/></Declaration $>$
$<$ SubClassOf $>$

$<$ Class IRI="\#Debt_to_Equity_Ratio"/>

$<$ Class IRI="\#Key_Performance_Indicators" $/></$ SubClassOf $>$

$<$ SubClassOf $>$

$<$ Class IRI="\#Debt_to_Equity_Ratio"/>

$<$ ObjectSomeValuesFrom $>$

$<$ ObjectProperty IRI="\#depends_on">>

$<$ Class IRI="\#Equity" $>$

$</$ ObjectSomeValuesFrom $>$

$</$ SubClassOf $>$

$<$ Class IRI="\#Debt_to_Equity_Ratio"/>

$<$ ObjectSomeValuesFrom $>$

$<$ ObjectProperty IRI="\#depends_on">>

$<$ Class IRI="\#Liabilities" $>>$

$</$ ObjectSomeValuesFrom $>$

$</$ SubClassOf $>$

$$
\text { .... }
$$

$</$ Ontology $>$ 
In this fragment of OWL code, the three parts can be distinguished: the declarations of concepts (for example: Debt_to_Equity_Ratio, Liabilities), the declarations of types of relations (for example: contains, depends_on), and the declarations of instances of relations (for example: Debt_to_Equity_Ratio depends_on Liabilities). The definitions of topics, relationships and instances are used by the above mentioned processes.

Usually business data contains a lot of explicit and hidden relationships that make their usage difficult. To interpret correctly the values of financial indicators, many measures and ratios need to be examined that either directly or indirectly influence the final result. Explicit visualization not only makes the interpretation of indicators easier, but it also contributes to finding explanations of current values of indicators.

\section{Design of Process ORIENTED ONTOLOGY}

The design of process oriented ontology has to provide not only a concise, comprehensive description of business processes but also express the semantics of processes in a formal way to be understood both by humans and the computer. In the project, a methodology of creating an ontology of financial knowledge, described in [6;7], has been applied. To obtain a complete view of financial knowledge, the specification of dynamic and procedural structures has to be added. The diagrammatic representation of BPD is insufficient to be translated into a system that will be able automatically to execute all these analytical processes. Many other tasks, such as retrieval, verification, or process composition, have to be done manually.

There are several languages to describe business processes such as UML, BPMN, BPEL, PSL, OWL-S, WSML, WISMO, etc. $[8 ; 9 ; 10 ; 11 ; 12]$. Taking into consideration a rigorous mathematical basis, close links with BPMN, and modelling facilities, Business Process Abstract Language (BPAL) has been chosen to specify procedural knowledge in processes of data analysis $[13 ; 14]$.

BPAL contains a number of modelling concepts, symbols and rules to define so called abstract processes. The syntax and semantics of BPAL constructs can be found in [13; 14]. Looking at specifications of BPAL processes, one may say that there are many similarities to the constructs in BPMN, but BPAL is not a diagrammatic notation. In general, BPAL Application Ontology is a collection of validated BPAL processes with respect to the BPAL Axioms, where Axioms represent the rules and constraints related to application processes. Business concepts in an application are defined using unary and relational predicates, called BPAL Atoms.

The process illustrated previously with BPMN can be defined as BPAL abstract specification as follows:

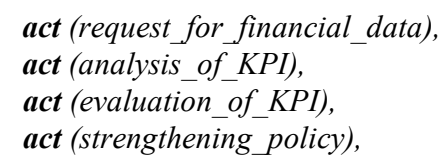

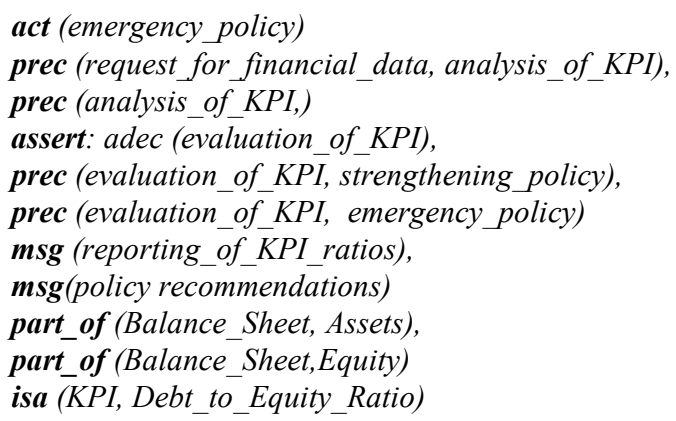

The key words in the specification mean the following [4]: act represents a business activity, prec indicates a precedence relation between activities, assert an assertion, msg a message sent and received. isa is a specialization relation, part_of - aggregation relation. An exclusive branch adec leads to the execution of exactly one successor, while an inclusive branch leads to the concurrent execution of a nonempty subset of its successors. The set of successors of exclusive or inclusive decision points may depend on conditions that usually take the form of tests on the value of the items that are passed between the activities.

The specification describes also the physical and the information items that are produced and consumed by the various activities during the execution of a process.

Formally, the created model of business processes has to contain not only a set of ground facts, predicates, but also a set of rules. The rules define among other things hierarchical relationships among the BPAL predicates, relationships among BPAL elements, properties, and item flow relations. The model of a process should respect a number of constraints related to the representation of activities, events, conditions, and exception handling [14]. The design of the analytical processes that illustrates these concepts will be detailed in the next section.

\section{USE CASE}

Improvement of the financial situation should be a dominant objective of any manager. In the use case, the analytical process of emergency policy will be presented and illustrated by the real data from financial information systems. The example is based on the general schema of processes related to the analysis of financial data (Fig.1).

For the purposes of the study, the decision making process supported by the i system was divided into six subprocesses as shown in Fig. 1.

Each of the indicated subprocesses will be described, including input, preconditions, activities, exception handling, postconditions, and output. Due to the limitations of the article length, only selected aspects of process modeling will be described.

The first subprocess concerns the request for financial data, in particular the data which is available in the financial statements. To illustrate the case, the basic information describing the financial situation of the company over three years is shown in Table 1 . 
TABLE I.

SELECTED FINANCIAL INFORMATION (IN K PLN)

\begin{tabular}{|l|r|r|r|r|r|}
\hline Specification & $\mathbf{2 0 1 4}$ & $\mathbf{2 0 1 5}$ & $\mathbf{2 0 1 6}$ & $\mathbf{2 0 1 7}$ & $\mathbf{2 0 1 8}$ \\
\hline Share capital & 600 & 600 & 600 & 600 & 600 \\
\hline Supplementary capital & 600 & 430 & 30 & 0 & 0 \\
\hline Net Income & -170 & -400 & -90 & -260 & -370 \\
\hline Long-term debt & 400 & 360 & 320 & 280 & 240 \\
\hline Short-term debt & 500 & 900 & 1300 & 1380 & 1500 \\
\hline Short-term receivables & 400 & 600 & 800 & 800 & 700 \\
\hline Investments and cash & 600 & 200 & 80 & 80 & 20 \\
\hline
\end{tabular}

After the requested information is obtained, the second subprocess is related to the evaluation of critical KPIs. The most important measure used in this analysis is Debt to Equity Ratio (see Fig. 1). Additionally, the liquidity ratios and other measures de-scribing corporate financial stability can be applied.

The system provides an internal report which serves as the input to the process 'Evaluation of KPIs'. The data included in the report refers to the most important measures of financial stability. Each manager can individually determine the content of the report or take advantage of the default solution. Assessment of KPIs is a very important component of the decision making process, but various common-size analysis and percentage change analysis may be also applied.

Subprocess 'Evaluation of KPIs' can be specified as follows:

input: Financial Data (share capital, supplementary capital, net income, long-term debt, short-term debt, shortterm receivables, and short-term investments including cash)

\section{preconditions:}

debt structure ratio $=$ total liabilities/total assets

debt structure ratio $>70 \%$

quick ratio= (accounts receivable + cash $) /$ short term liabilities

quick ratio $<1$

activities

assessment of current financial standing of the company

based on debt structure ratio, debt to equity ratio,

liquidity ratios

exception handling: lack of data values

postconditions: negative or positive assessment of debt to equity ratio

output: Emergency policy or Strengthening Policy

The most important outcome from this process is the recommendation with respect to the financial standing of the company. In the analyzed company, Debt to Equity Ratio of $200 \%$ indicates extremely high financial leverage. Thus, the situation of a company is definitely perceived as highly unfavorable, because the company is likely to have serious problems with servicing its financial obligations in the future.

Taking into account the necessity to complete the process, the manager has two options. If Debt to Equity Ratio is on the satisfactory level, the company should go back to normal activities. If the ratio exceeds $200 \%$, then the procedure for reducing financial risk should be initiated. Such a high level of debt to equity ratio is a clear sign of the extremely unfavorable financial situation of the company. The system based on Debt to Equity Ratio analysis generates a signal indicating excessive debt. This suggestion prompts the carrying out of the subsequent subprocess called 'Forecasting of sales revenues and free cash flows'.

Sales forecasting as well as the company's ability to generate excess cash are both essential elements of overall company management A company forecast to encounter excessive debt needs to search for corrective measures. The basis for this subprocess is a report containing financial data and KPIs as described in the previous subprocess.

\section{Subprocess Forecasting of sales revenues and free cash} flows

input: Financial statement data, KPIs values

preconditions:

debt to equity ratio $>200 \%$

activities:

- preparation of the forecast financial statements: the amount of future liabilities, potential minimum amount of free cash flow (linear forecasting model)

- estimation of the debt to equity ratio on the forecast financial statement

- assessment of forecast ratios

exception handling: registration of new contracts aimed to increase sales revenue

postconditions: forecast debt to equity ratio $<200 \%$

output: Financial recovery program or Requesting of new sources of financing

The forecast can be used to provide warning signals. The values presented in Table 1 (last 2 columns) indicate that the forecast Debt to Equity Ratio (> 200\%) significantly exceeds the safety level.

Information included in the forecast does not permit the introduction of a financial recovery program and its normal operation. It is necessary to look for new solutions created in the subprocess 'Requesting of new sources of financing'. This sub-process requires a response from the manager. Thus it is necessary to obtain information on banking offers. The key information refers to the terms and conditions of bank loans.

Sub-process: Requesting new sources of financing input

Bank and Credit Institution list of offers and financing conditions

Report on corporate credibility

preconditions: unsatisfactory financial forecast activities:

- analysis of offers and financing conditions

- checking of financial standing of company

- selection of the best offers

- request of manager decision (accept or reject)

exception handling: obtain of short-term credit lines (3 months)

postconditions: acceptance or rejection from bank or credit institution

output: financial recovery program or suggestion necessity applying for public aid 
Before granting a loan, each bank shall determine the loan conditions concerning the interest rate, loan period, additional charges, and safety. Analysis of bank offers is conducted against the financial situation of the company. It is necessary to verify the terms of loan in the context of the company's credibility. If there is more than one suitable offer, a manager has to choose the most favorable loan and send the application to the selected bank.

In the case of a negative decision from the bank, the system initiates the next process 'Applying for public aid'. As in the previous subprocess, it is necessary to check all available aid funds. Specification of this subprocess is as follows:

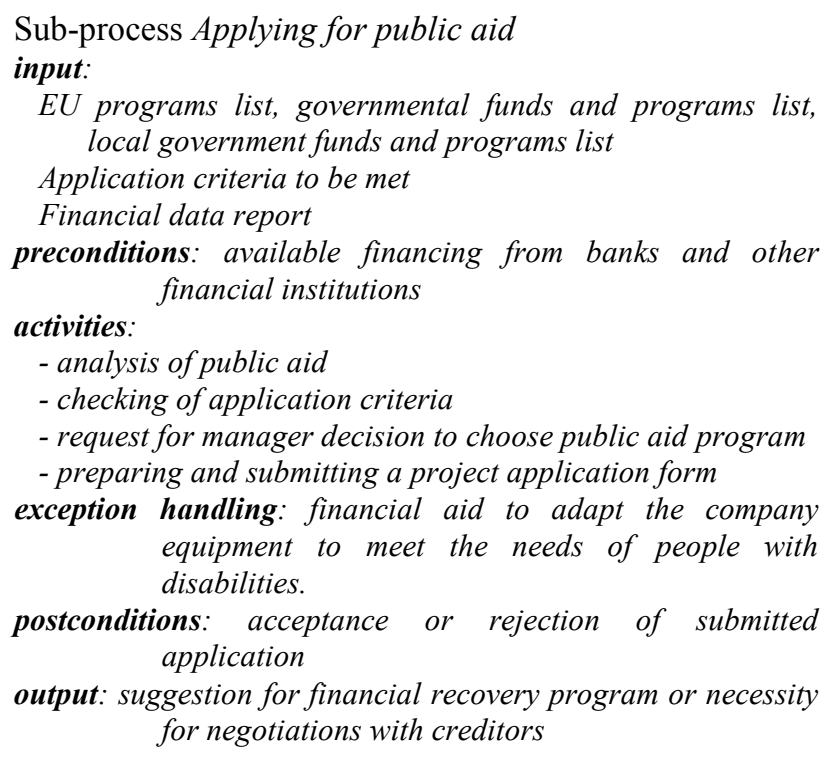

Financial aid is a solution dedicated only for selected companies. External institutions offer additional aid funds on the basis of very strict criteria. The manager has to analyze the available opportunities after providing the system with the required data related to public assistance. If the system generates a support program tailored to the needs of the enterprise, the manager will be asked to prepare and submit applications. If the application is rejected, then it is necessary to execute the next subprocess.

Unfortunately, due to the poor financial situation, it may be that the company cannot receive an external financial aid. Thus, the last step will be focused on negotiations with creditors to improve the financial situation of the company. Negotiations with creditors are the last chance for the company to survive. The subprocess can be specified as follows:

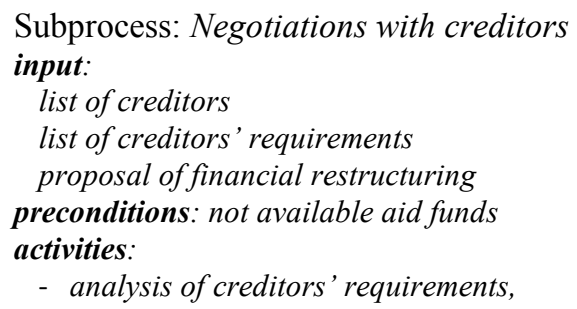

- preparing and submission of restructuring program

- negotiations with creditors

- preparing the contract on conversion of liabilities into equity

exception handling: ownership changes of creditors postconditions: acceptance or rejection

output: suggest necessity of converting liabilities into equity or the commencement of bankruptcy procedure

The starting point in the negotiation process is to recognize the creditors' requirements. Creditors may expect to obtain a specific number of shares instead of debt reduction. Creditors generally expect the managers to conduct the restructuring program for the company. These two elements serve as the basis to begin the process of conversion of liabilities into equity. If the conditions for conversion are accepted by both parties, then the relevant agreement is processed. Negotiations with creditors are the last chance to avoid bankruptcy. The creditors' agreement for the conversion of liabilities into equity can be the only possibility for the company to survive. If there is no opportunity to reduce excessive debt, then the company is likely to go bankrupt in a legal sense. As shown in the example, the conversion of liabilities into equity should be immediately negotiated even if this is unfavorable for the current owners.

The presented use case illustrates an approach to the automation of the process of decision making support. The integration of external sources of information with the contextual internal data is a way of reducing uncertainty in the decision process. The identification of analytical activities as well as assigning a minimum set of information is a relatively new approach to analytical work automation. The conducted preliminary study may serve as the basis for the use of a process-oriented methodology in the decisionmaking analysis. The use of process-oriented knowledgebased systems allows managers to make better business decisions.

\section{V.CONCLUSION AND FUTURE WORKS}

The idea of the paper to enrich the financial knowledge by presenting formally specified business processes has been achieved. The approach was applied to real-world scenarios coming from financial analysis. In the design, it was made possible to merge the procedural and ontological perspectives and to express process-related knowledge by using standard modeling languages such as BPMN, OWL, and, for reasoning and execution, BPAL and BPEL. The use of formal notations assured a mathematical rigor in process descriptions and the precise definition of concepts and relationships in the domain knowledge. In providing the formally written financial ontology, the sources of ambiguity and confusion were considerably reduced.

Currently there are many process modeling notations, e.g. BPMN, EPC, XPDL, and Petri nets. From the functional viewpoint, they should be interoperable, in order to 
overcome heterogeneities of different formalisms and map them to one common, machine-interpretable, process ontology. In addition, the solutions should provide interrelations to existing domain ontologies, and enable query and search facilities.

Giving consideration to a formal account of BPMN, BPAL seemed to us an appropriate choice to automate the use of business process knowledge. BPAL remains at an abstract level, since it relies on BPMN for its concrete diagrammatic representation and on BPEL for its actual execution. The formally written BPAL specifications can then be automatically translated into executable programs BPEL and perform the reasoning and interpretation of financial information.

We are convinced that the abstract language of process specification provides a declarative and procedural semantics that can be interpreted, processed, and executed as a BPEL.

The experiments we have conducted are encouraging and revealed practical usability and its acceptance by business experts.

From the financial viewpoint, the presented use case leads to the conclusion that the conversion of liabilities into equity should be carried out when there is a dominant owner with high potential for raising capital. The reduction of financial liabilities is highly desirable in order to improve financial standing, but it cannot be done at any price. The considerations contained in this paper underline the need for in-depth analysis of the conversion of financial liabilities into equity.

Further work should be focused on a comprehensive process-oriented approach to problem solving in enterprises. Each decision-making problem should be decomposed to subprocesses and activities, and associated with relevant information. This would not be possible without the use of knowledge possessed by experienced managers and financial analysts. The process oriented approach implemented in the decision support system helps one to achieve a competitive advantage for the company. The use of process-based knowledge may also contribute to increasing the financial stability of corporates.

\section{REFERENCES}

[1] T. Beck and A. Dermirguc-Kunt, "Small and medium-size enterprises: Access to finance as a growth constraint", Journal of Banking and Finance, 2006, vol. 30, no. 11, pp. 2931-2943
[2] J. Korczak, H. Dudycz, B. Nita, P. Oleksyk and A. Kaźmierczak, “Attempt to extend knowledge of Decision Support Systems for small and medium-sized enterprises", in: Proc. of the 2016 Federated Conference on Computer Science and Information Systems, M. Ganzha, L. Maciaszek, M. Paprzycki, Eds., Annals of Computer Science and Information Systems, vol. 8, 2016, pp. 1263-1271, DOI:10.15439/2016F 181

[3] F. Smith and M. Proietti, "BPAL: A Platform for Managing Semantically Enriched Conceptual Process Models", in: eChallenges e-2014 Conference Proceedings IIMC International Information Management Corporation, P. Cunningham, M. Cunningham, Eds., 2014

[4] A. De Nicola, M. Lezoche, and M. Missikoff, "An Ontological Approach to Business Process Modeling", in: 3th Indian International Conference on Artificial Intelligence, 2007, pp. 1794-1813

[5] T. J. O'Brien, K. L. Schmid and J. Hilliard, "Capital Structure Swaps and Shareholder Wealth", European Financial Management, 2007, vol. 13 , no. 5

[6] H. Dudycz and J. Korczak, "Process of Ontology Design for Business Intelligence System", in: Information Technology for Management, E. Ziemba, Ed., LNBIP Springer, 2016, pp.17-28

[7] H. Dudycz and J. Korczak, "Conceptual design of financial ontology", in: Proc. of the 2016 Federated Conference on Computer Science and Information Systems, M. Ganzha, L. Maciaszek, M. Paprzycki, Eds., Annals of Computer Science and Information Systems, vol. 5, 2015, pp. 1505-1511; DOI:10.15439/978-83-60810-66-8

[8] W. Abramowicz, A. Filipowska, M. Kaczmarek and T. Kaczmarek, "Semantically Enhanced Business Process Modeling Notation", in: Semantic Technologies for Business and Information Systems Engineering: Concepts and Applications, S. Smolnik, F. Teuteberg, O. Thomasal. Eds., 2012, pp. 259-275

[9] OWL-S: Semantic Markup for Web Services, W3C Member Submission, 2004, D. Martin, Ed., http://www.w3.org/Submission/OWL-S/

[10] M. Born, A. Filipowska, M. Kaczmarek, I. Markovic and M. Starzecka, "Business Functions Ontology and its Application in Semantic Business Process Modelling", in: Proc. ACIS, 2008, pp. 136-145

[11] D. Fensel, H. Lausen, A. Polleres, J. de Bruijn, M. Stollberg, D. Roman, and J. Domingue, Enabling Semantic Web Services: The Web Service Modeling Ontology, Springer, 2007

[12] D. Calvanese, G. De Giacomo, D. Lembo, M. Montali and A. Santoso, "Ontology-Based Governance of Data-Aware Processes", in: Proc. of the $6^{\text {th }}$ Int. Conf. on Web Reasoning and Rule Systems, LNCS 7497, Springer, Heidelberg, 2012, pp. 25-41

[13] F. Smith and M. Proietti, "Rule-based Behavioral Reasoning on Semantic Business Processes", in: Proc. of the 5th Int. Conf. on Agents and Artificial Intelligence, SciTePress, 2013

[14] F. Smith and M. Proietti, Ontology-based Representation and Reasoning on Process Models: A Logic Programming Approach, 2014, https://arxiv.org/abs/1410.1776 